\title{
Correction to: Comparative experimental and numerical study on the mechanical properties, formability, and microstructure of two high strength steel sheets
}

\author{
Ali Basaeri $^{1} \cdot$ H. Khorsand ${ }^{1} \cdot$ R. Eslami-Farsani ${ }^{1}$ - M. H. Hasanniya ${ }^{2}$ \\ Published online: 9 June 2020 \\ (C) Springer-Verlag London Ltd., part of Springer Nature 2020
}

Correction to: The International Journal of Advanced Manufacturing Technology

https://doi.org/10.1007/s00170-020-05399-3

This original article contained a mistake.

Author name "M. A. Basaeri" should be presented as "Ali Basaeri" as correctly shown above.

The original article has been corrected.

Publisher's note Springer Nature remains neutral with regard to jurisdictional claims in published maps and institutional affiliations.

The online version of the original article can be found at https://doi.org/ $10.1007 / \mathrm{s} 00170-020-05399-3$

Ali Basaeri

M.ali.basaeri@gmail.com

1 Faculty of Materials Science and Engineering, K. N. Toosi University of Technology, Tehran, Iran

2 Materials Research \& Engineering Department, SAPCO, Tehran, Iran 